\title{
Application of Hydrological Computations in Predicting Rainfall Trends in Owerri Imo State of Nigeria
}

\author{
Lawrence E. Obi
}

\begin{abstract}
This research employed the empirical method in its approach and workings. Empirical data were collected and various hydrological computations and graphs were engaged through the application of the collected data. The mass curve of rainfall, hyetograph, moving average of annual rainfalls and the computations of recurrence intervals were done by applying the Weibull formula. With computations and its subsequent analysis, the recurrent intervals of rainfall magnitudes were determined and rainfall pattern within Imo State were predicted.
\end{abstract}

Index Terms-Hydrology; Hydrometeorology; Prediction; Rainfall.

\section{INTRODUCTION}

Rainfall is a critical component in the normal water cycle. Rainfall can be said to be central to the other components of the water cycle. Rainfall provides recharge to the groundwater aquifers and it can be described as an indispensable element in the sustainability of groundwater. Rainfall boosts the discharge capacity of rivers during the wet season. This enhances the ability of rivers to serve the purposes of electricity generation, irrigation, water supply and mitigation of drought.

The rainfall data have proved useful in the integrated water resources management and the availability of water in the catchment area. With rainfall data, effective and efficient drains are designed and it helps to give bridges their required a hydraulic head. Flood control measures are designed with the value of rainfall intensities in any catchment area. The amount of rainfall determines the types of crops that thrive in an area and the period of farming. All crops have their water intake capacities and when the optimal amount of water is provided for them, they grow luxuriantly with consequences of bountiful harvest. Rainfall pattern has been playing an increasing and important role in weather forecast and early warning signals to farmers and communities who live along the paths of potential disasters caused by climatic changes. Such disasters as droughts, tropical storms and unpredicted rainfalls with its attendant flooding and erosion are occurrences that can easily be remembered. A good understanding of hydrometeorology backed with periodic and reliable data gathering based on the regular measurement of the basic meteorological parameters such as rainfall, temperature, humidity sunshine, evaporation, wind velocity and direction, proffer an effective analysis and predictions of climatic trends and the expected problems. Adequate information to the public

Published on September 23, 2017.

L. E. Obi is with the Civil Engineering Department, Imo State University, Owerri, Imo State, Nigeria. (e-mail: engrlawobi@yahoo.com) about rainfall will send early warning to people such as farmers who may be adversely affected by climatic changes.

The mean value of rainfall is a representative value which can easily be associated with rainfalls within a periodic framework. The comparative analysis of mean rainfall values determined with various methods will enable the most efficient method to be adopted [1]-[3].

\section{A. Precipitation}

Precipitation can be defined as water which comes back to the surface of the earth in its various forms of rain, mist, snow, hail and sleet. Water evaporates from water surfaces like rivers, oceans, streams, ponds lakes, springs etc. and also from the earth surface and plants in the form of water vapour. The water vapour accumulates on the atmosphere and behaves like a gas. In the normal range of pressure and temperature, the water vapour obeys the gaseous laws of Boyle and Charles. With the accumulation of water, the water vapour may increase so much that there will be no available space to accommodate its further increase. At this point there will be condensation and when the condensed water is released there will be rainfall. However, it should be noted that the water vapour may get condensed in different forms rain, mist, hail, snow sleet etc. and when it is release there will be a fall of snow, rain mist, hail or sleet.

Rainfall takes the greatest part of precipitation while a minor part is in the form of snow. The other forms of precipitation hail, sleet, mist are very small and are always ignored in the design of hydrological works. Due to the fact that their values are insignificant they are not important in design. Actually, for precipitation to form these conditions must be fulfilled namely; atmosphere must have moisture, there must be adequate nuclei (i.e. particles) to aid condensation, favourable weather conditions for condensation of water vapour by adiabatic cooling of air mass and the end products of condensation must reach the earth. The nuclei (particles) are salt particles or suspended particulate matter obtained from burning of fossil fuel. The wind speed enhances the movement of clouds and the turbulence created thereby retains the water droplets in suspension. Precipitation takes place when droplets come together and coalesce to form bigger droplets which then falls as precipitation to the earth [1],[3].

\section{Types of Precipitation:}

There are about four types of precipitation namely; convectional, frontal, orographic and cyclonic precipitation. Convectional precipitation can also be called thermal convection and it is in the forms of local whirling thunder storms and it is a characteristic of the tropics. It is formed by the rising of the warm air (which is heated due to its proximity to the earth) as a result of its low weight per unit 
volume and cools adiabatically to form a cauliflower shaped cloud which later explodes in to a thunder storm. It may be followed by devastating and destructive winds and this happens the wind is known as tornados.

Frontal precipitation occurs as a result of conflict between two air masses. The meeting or clashing of two air masses with different and contrasting temperatures and densities results to condensation and consequently precipitation at the surface of contact. The surface of contact is called a front or frontal surface. When a cold air drives away a warm air mass, the surface of contact created is called a cold front while when a warm mass drives away cold air mass, a warm front. Cold front produces intense precipitation on small areas while the warm front results to less intense precipitation which falls on a large area. Cold front overtakes warm front resulting in the formation of a front where the cold air mass is sliding against warm air mass and this formation is known as occlusion or occluded front.

Orographic precipitation occurs a result of the mechanical lifting moist air over mountainous barriers. The orographic precipitation is normally heavy on the direction of the wind. The cyclonic precipitation occurs as a result of the lifting of moist converging into a low pressure region. The precipitation takes due to the pressure differences created by the unequal heating of the earth surface. In the occurrence cyclonic precipitation, the winds blow spirally inward anticlockwise in the northern hemisphere and clockwise in the southern hemisphere. Cyclonic precipitation exists in two forms namely tropical cyclones called hurricane or typhoon and the extra-cyclone with large diameter widespread frontal type of precipitation [1],[3].

\section{B. Hydrometeorology}

Hydrometeorology can be defined as the branch of meteorology and hydrology that treats the transfer of water and energy between the land surface and the lower atmosphere (i.e. the troposphere). At the troposphere, temperature decreases with increasing height at the rate of $50 \mathrm{C} / \mathrm{km}$ (called the lapse rate). This drop in temperature is due to the fact that the main source of heat in the troposphere is the absorbed solar radiation from the ground surface.

The troposphere contains most of the water vapour, clouds and storms and it is responsible for $75 \%$ of the weight of the atmosphere. At the troposphere, winds are generated and clouds are formed and this causes precipitation and the troposphere is responsible for meteorological processes [5].

UNESCO has many programmes and activities that handle the study of natural hazards of hydrometeorological origin and the mitigation of their effects. These hazards include the results of natural processes or phenomena of atmospheric, hydrological or oceanographic nature such as floods tropical cyclones, droughts and desertification. Hydrometeorology tries to bring together the troposphere, climate, weather and the community together. Previously, hydrometeorology was limited to weather but its coverage has been extended to space through the use of satellites, or rockets and spaceships. Weather can be defined generally as the state of the atmosphere at a place and time with regards to heat, dryness, sunshine, wind, rain while climate is the composite or generally prevailing weather conditions of a place such as its temperature, air pressure, humidity, precipitation, sunshine, cloudiness and winds, throughout the year, averaged for a number of years. The climate is the sum of all weather events in an area through a long period of time. The climate of an area is primarily obtained by the long term temperature and precipitation records of the area. The difference between weather and climate is that while weather is the condition of the atmosphere during a brief period (as it may change from day to day), the climate indicates the weather of the area over many years [5]-[7].

\section{Rainfall}

Rainfall is the liquid part of precipitation which is released to the ground from the atmosphere. The condensation of the water vapour in the atmosphere forms clouds or fogs. The cloud formed by the cooling and condensation of rising water vapour disintegrates itself into some minute aggregates of particles called droplets and ice. When these droplets and ice are saturated and heavy in the atmosphere, they are released to the earth as rain, ice, mist etc. The type of rain or precipitation obtained depends on the type of cloud formed. Rain is the major precipitation we have in Nigeria.

\section{Measurement of Rainfall}

Rainfall is mainly measured with an instrument called rain gauges. In order to estimate the effect of precipitation, it is only reasonable to measure the amount of precipitation and its distribution. All forms of precipitation are measured as the vertical depth of water that would accumulate on a level ground if all the water are restricted where they fell. The total amount of precipitation of a place in a given time, is expressed as the depth to which it would accumulate on the horizontal projection of the surface provided there were no losses by evaporation and runoff.

Due to the fact that amount of rainfall varies from place to place, it is vital to install measuring devices (rain gauges) at various key points in the area and the points where the rainguages are installed is called rainguage stations. The rainfall is normally measured in millimetre $(\mathrm{mm})$.

\section{Statistics as an Instrument of Hydrology}

Statistics is a science of collecting information discretised in numbers called data. The role of statistics in science and engineering cannot be over-stated. It is indispensable in data collection, analysis and interpretation. Statistics has a major place in research as it is often used by researcher to develop concepts empirically and undertake objective analysis based on facts resulting to deductive and accurate conclusions and results. It plays a major part in erasing doubts over experimental uncertainties and confusion.

Statistical instrument used in science and engineering includes graphs and computer software. Such concepts as mean, average, deviation, frequencies, mode, medium, skewness, range, dispersion, quartile, etc are commonly employed in statistical analysis. The statistical procedures involve computation of data resulting to mean, median, mode, standard deviation, skewness, dispersion and these are regarded as statistical parameters. The graphical instruments of statistics include histogram, bar chart, pie 
chart, etc. and these are important tools applied in engineering analysis and hydrology [4],[6],[7].

\section{E. Rainfall Pattern in Nigeria}

Nigeria is a large country with high population whose wetness reduces from the southern part to the Northern region. There is a wide variability of rainfall between the southern and northern parts of the country. Actually, rainfall varies with latitude, elevation, topography, seasons, distance from the sea and coastal sea surface temperature. Nigeria is characterized with tropical climate of hot and wet conditions associated with the movement of inter-tropical convergence of zone (ITCZ) north and south of the equator.

The wet season in Nigeria starts in March and ends in October while the dry season lasts from November to February. With the rainy and dry season durations it can be inferred that there is a longer time for the rains than the dryness period. While there is a general decrease in rainfall in Nigeria, the coastal area is experiencing slight increase. The decrease in rainfall has ecological destabilization and changed the vegetation pattern especially in the northern part of Nigeria. The rainfall pattern has also enhanced wind erosion and desertification, soil erosion and wastal flooding in the north east and coastal areas of the country.

Nigeria's climate is seasonally humid and damp and it is affected by four climate types. The climate types are distinguishable as one moves from the northern part of Nigeria to the southern part through the middle belt. The southern part experiences heavy and abundant rainfall. These storms are usually convectional in nature due to the regions proximity to the equatorial belt. The annual rainfall in the southern region is high usually above $2000 \mathrm{~mm}$ but it is higher in the coastal range to the tune of over $4000 \mathrm{~mm}$ annually [2],[4].

\section{METHODOLOGY}

The analytical and empirical approaches were used in the research. Rain gauging stations were established with the relevant equipment such as the rainguages and the data collected were applied in computations.

\section{A. Data Collection}

Data were collected from the rainguage stations on a daily basis. The data were appropriately arranged and recorded.

\section{B. Data Analysis}

The data were analysed using the hydrological and statistical instruments of mass curve, moving average curve and recurrence interval commutation.

The primary data of rainfall and duration are used to obtained the rainfall intensity thus:

$$
\text { Rainfall intensity }=\frac{d p}{d t}
$$

The hyetograph is a bar diagram plotted between the average intensity of rainfall as ordinate and the time as the abscissa. The moving average curve is the graph of annual precipitation values as the ordinate and the respective years as the abscissa, with a 3- year moving mean thus:

$$
\begin{aligned}
& P_{1}=\frac{P_{1}+P_{2}+P_{3}}{3}, P_{2}=\frac{P_{2}+P_{3}+P_{4}}{3}, P_{3}=\frac{P_{3}+P_{4}+P_{5}}{3} \\
& P_{n}=\frac{P_{n}+P_{n+1}+P_{n+2}}{3}
\end{aligned}
$$

The mass curve of rainfall is obtained by plotting the graph of cumulative rainfall against time. The recurrent interval computation is obtained through this procedure;

Probability, $P=\frac{1}{T_{r}}$

Frequency, $f=100 p=\frac{100}{T_{r}}$

Probability of occurrence at least once (Risk), Z,

$Z=1-(1-P)^{N}$

Probability of non-occurrence in N-successive year's X,

$X=(1-P)^{N}$

Recurrent Interval $\mathrm{T}_{\mathrm{r}}$ for rainfall of the rank $\mathrm{m}$ is given by Weibull formula,

$T_{r}=\frac{n+1}{m}$

\section{RESULTS AND ANALYSIS}

\section{A. Results}

The results of rainfall with their average values in Imo

\begin{tabular}{|c|c|c|c|c|c|c|c|c|c|c|c|c|c|c|}
\hline \multirow[b]{2}{*}{ Year } & \multicolumn{14}{|c|}{ Amount of Rainfall (mm). } \\
\hline & Jan. & Feb. & March & April & May & June & July & Aug. & Sept. & Oct. & Nov. & Dec. & $\begin{array}{l}\text { Max } \\
\text { Rainfall }\end{array}$ & $\begin{array}{l}\text { Average } \\
\text { Rainfall }\end{array}$ \\
\hline 2000 & 39.1 & 0.0 & 53.2 & 354.2 & 47.3 & 391.8 & 382.7 & 356.4 & 344.0 & 246.5 & 116.5 & 5.5 & 391.8 & 194.8 \\
\hline 2001 & 5.5 & 62.0 & 206.4 & 172.2 & 140.8 & 385.4 & 301.7 & 348.7 & 430.8 & 213.4 & 22.6 & 14.8 & 430.8 & 132.0 \\
\hline 2002 & 0.2 & 27.9 & 90.4 & 241.7 & 265.6 & 345.6 & 391.5 & 294.2 & 261.9 & 225.8 & 91.0 & 1.7 & 391.5 & 186.5 \\
\hline 2003 & 42.3 & 92.6 & 136.9 & 73.3 & 278.1 & 277.4 & 439.5 & 379.2 & 476.4 & 123.8 & 50.6 & 0.2 & 476.4 & 137.5 \\
\hline 2004 & 6.1 & 32.4 & 67.4 & 258.8 & 268.9 & 298.2 & 327.0 & 384.4 & 305.1 & 260.3 & 56.7 & 0.2 & 384.4 & 188.8 \\
\hline 2005 & 35.5 & 58.4 & 102.6 & 194.3 & 359.8 & 367.0 & 380.6 & 302.4 & 232.9 & 199.8 & 13.9 & 0.2 & 380.6 & 187.3 \\
\hline 2006 & 78.5 & 48.4 & 108.1 & 104.1 & 157.3 & 349.9 & 397.6 & 232.1 & 537.6 & 303.3 & 33.3 & 0.0 & 537.6 & 195.9 \\
\hline 2007 & 0.2 & 7.4 & 57.7 & 62.1 & 260.9 & 397.3 & 485.4 & 509.0 & 303.0 & 180.2 & 42.7 & 9.6 & 509.0 & 193.0 \\
\hline 2008 & 13.6 & 0.0 & 117.5 & 215.4 & 209.7 & 473.9 & 630.2 & 289.6 & 449.8 & 382.9 & 9.2 & 26.2 & 630.2 & 234.8 \\
\hline 2009 & 38.6 & 71.4 & 71.2 & 242.8 & 441.5 & 239.0 & 497.9 & 539.2 & 485.3 & 236.8 & 115.4 & 0.0 & 539.2 & 248.3 \\
\hline 2010 & 0.0 & 62.5 & 34.1 & 164.2 & 297.5 & 255.2 & 252.0 & 453.8 & 258.4 & 306.6 & 18.4 & 1.6 & 453.8 & 175.4 \\
\hline 2011 & 0.0 & 133.7 & 84.4 & 114.8 & 528.3 & 189.3 & 305.2 & 506.7 & 366.0 & 241.2 & 49.7 & 24.8 & 528.3 & 212.0 \\
\hline
\end{tabular}
State from the year 2000 to 2016 are presented in Table I.

TABLE I: RAINFALL DATA IN OWERRI IMO STATE FROM 2000 - 2016 


\begin{tabular}{lllllllllllllll}
\hline \hline 2012 & 0.2 & 74.1 & 22.1 & 158.0 & 249.2 & 284.2 & 430.2 & 316.0 & 483.1 & 175.9 & 113.2 & 0.0 & 483.1 & 192.2 \\
\hline 2013 & 0.0 & 40.0 & 130.9 & 190.5 & 253.2 & 188.7 & 254.1 & 409.1 & 279.0 & 101.1 & 48.6 & 132.4 & 409.1 & 169.0 \\
\hline 2014 & 0.0 & 21.4 & 100.2 & 157.0 & 289.4 & 236.2 & 139.3 & 336.3 & 355.6 & 220.7 & 91.3 & 30.0 & 355.6 & 164.8 \\
\hline 2015 & 12.4 & 72.2 & 61.0 & 61.4 & 236.6 & 364.7 & 325.8 & 359.2 & 352.9 & 324.3 & 78.1 & 0.0 & 364.7 & 187.4 \\
\hline 2016 & 0.0 & 29.4 & 192.5 & 143.9 & 157.4 & 272.6 & 378.1 & 409.4 & 423.8 & 144.7 & 12.2 & 0.2 & 423.9 & 180.4 \\
\hline \hline \multicolumn{8}{c}{ Source: NIMET, Imo Airport, 2017 } & \multicolumn{1}{c}{$c$} & &
\end{tabular}

A table of the cumulative rainfall and the durations for the monitored storm is shown in Table II.

TABLE II: CUMULATIVE RAINFALL FOR 12 - HOUR STORM

\begin{tabular}{lccc}
\hline S/N & $\begin{array}{c}\text { Rainfall } \\
(\mathbf{m m})\end{array}$ & $\begin{array}{c}\text { Duration } \\
\text { Hours }\end{array}$ & $\begin{array}{c}\text { Cumulative Rainfall } \\
(\mathbf{C m})\end{array}$ \\
\hline 1 & 0.5 & 1.1 & 0.5 \\
\hline 2 & 0.8 & 1.2 & 1.3 \\
\hline 3 & 1.0 & 1.5 & 2.3 \\
\hline 4 & 1.8 & 1.8 & 4.1 \\
\hline 5 & 3.0 & 2.0 & 7.1 \\
\hline 6 & 5.5 & 2.2 & 12.6 \\
\hline 7 & 7.3 & 2.7 & 19.9 \\
\hline 8 & 21.5 & 4.0 & 41.4 \\
\hline 9 & 27.2 & 4.2 & 68.6 \\
\hline 10 & 42.5 & 5.0 & 111.1 \\
\hline 11 & 56.7 & 6.1 & 167.8 \\
\hline 12 & 73.5 & 7.5 & 241.3 \\
\hline 13 & 72.2 & 8.3 & 313.5 \\
\hline 14 & 70.5 & 8.6 & 384.0 \\
\hline 15 & 50.0 & 9.8 & 434.0 \\
\hline 16 & 32.0 & 10.0 & 466.0 \\
\hline 17 & 22.8 & 11.4 & 488.2 \\
\hline \hline
\end{tabular}

\begin{tabular}{cll}
\multicolumn{2}{c}{ TABLE III: MOVING AVERAGE RAINFALL FOR 17 YEARS } \\
\hline \hline S/N & Year & \\
\hline 1 & 2000 & 171.1 \\
\hline 2 & 2001 & 150.2 \\
\hline 3 & 2002 & 170.9 \\
\hline 4 & 2003 & 171.2 \\
\hline 5 & 2004 & 190.7 \\
\hline 6 & 2005 & 192.1 \\
\hline 7 & 2006 & 207.9 \\
\hline 8 & 2007 & 225.4 \\
\hline 9 & 2008 & 219.5 \\
\hline 10 & 2009 & 211.9 \\
\hline 11 & 2010 & 193.2 \\
\hline 12 & 2011 & 191.1 \\
\hline 13 & 2012 & 175.3 \\
\hline 14 & 2013 & 173.7 \\
\hline 15 & 2014 & 177.5 \\
\hline 16 & 2015 & 183.9 \\
\hline 17 & 2016 & 180.4 \\
\hline \hline
\end{tabular}

The recurrence interval for seventeen years in Imo State is computed and presented in Table IV.

In order to establish a trend in the rainfall, a Moving Average Table is developed for the basin thus,

TABLE IV: RECURRENCE INTERVAL FOR 17 YEARS RAIN IN OWERRI IMO STATE.

\begin{tabular}{|c|c|c|c|c|c|c|}
\hline $\begin{array}{c}\text { S/N } \\
(1)\end{array}$ & $\begin{array}{c}\text { Year } \\
(2)\end{array}$ & $\begin{array}{c}\text { Precipitation } \\
\text { (mm) } \\
\text { (3) }\end{array}$ & $\begin{array}{c}\text { Ranking } \\
\text { (m) } \\
(4)\end{array}$ & $\begin{array}{c}\text { Recurrence } \\
\text { Interval (years) } \\
T_{r}=\frac{n+1}{m} \\
\text { (5) }\end{array}$ & $\begin{array}{c}\begin{array}{c}\text { Probability of } \\
\text { Occurrence } \\
\\
\quad P=\frac{1}{T_{r}}\end{array} \\
\text { (6) }\end{array}$ & $\begin{array}{c}\text { Frequency of } \\
\text { Occurrences, f = 100p } \\
(\%) \\
(7)\end{array}$ \\
\hline 1 & 2009 & 248.3 & 1 & 18.0 & 0.06 & 6.00 \\
\hline 2 & 2008 & 234.8 & 2 & 9.0 & 0.11 & 11.00 \\
\hline 3 & 2011 & 212.0 & 3 & 6.0 & 0.17 & 17.00 \\
\hline 4 & 2006 & 195.9 & 4 & 4.5 & 0.22 & 22.00 \\
\hline 5 & 2000 & 194.8 & 5 & 3.6 & 0.28 & 28.00 \\
\hline 6 & 2007 & 193.0 & 6 & 3.0 & 0.33 & 33.00 \\
\hline 7 & 2012 & 192.2 & 7 & 2.6 & 0.38 & 38.00 \\
\hline 8 & 2004 & 188.8 & 8 & 2.3 & 0.43 & 43.00 \\
\hline 9 & 2015 & 187.4 & 9 & 2.0 & 0.50 & 50.00 \\
\hline 10 & 2005 & 187.3 & 10 & 1.8 & 0.56 & 56.00 \\
\hline 11 & 2002 & 186.5 & 11 & 1.6 & 0.63 & 63.00 \\
\hline 12 & 2016 & 180.4 & 12 & 1.5 & 0.67 & 67.00 \\
\hline 13 & 2010 & 175.4 & 13 & 1.4 & 0.71 & 71.00 \\
\hline 14 & 2013 & 169.0 & 14 & 1.3 & 0.76 & 76.00 \\
\hline 15 & 2014 & 164.8 & 15 & 1.2 & 0.83 & 83.00 \\
\hline 16 & 2003 & 137.5 & 16 & 1.1 & 0.91 & 91.00 \\
\hline 17 & 2001 & 132.0 & 17 & 1.1 & 0.91 & 91.00 \\
\hline
\end{tabular}




\section{B. Hydrological Graphs}

With the information on Table II, the time - intensity (i.e. hyetography) can be drawn as shown in Fig 1.

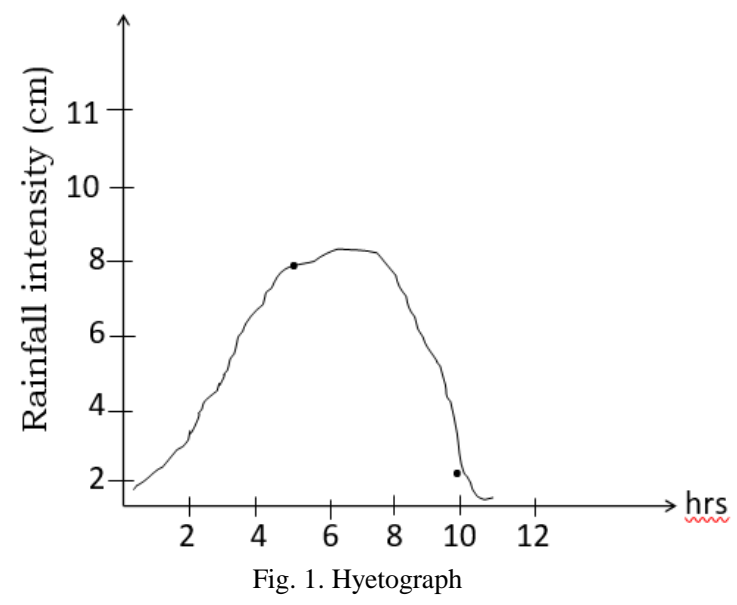

With Table III, the mass curve of a monitored storms in the state can be drawn as shown in Fig. 2.

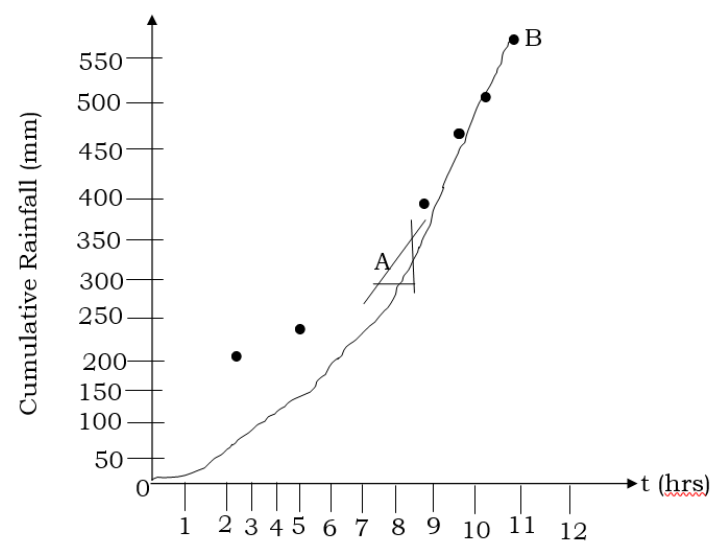

Fig. .2. Mass curve of the monitored storm A.

3 - year moving Average curve of Annual Rainfalls in the state was drawn and it is shown in Fig 3.

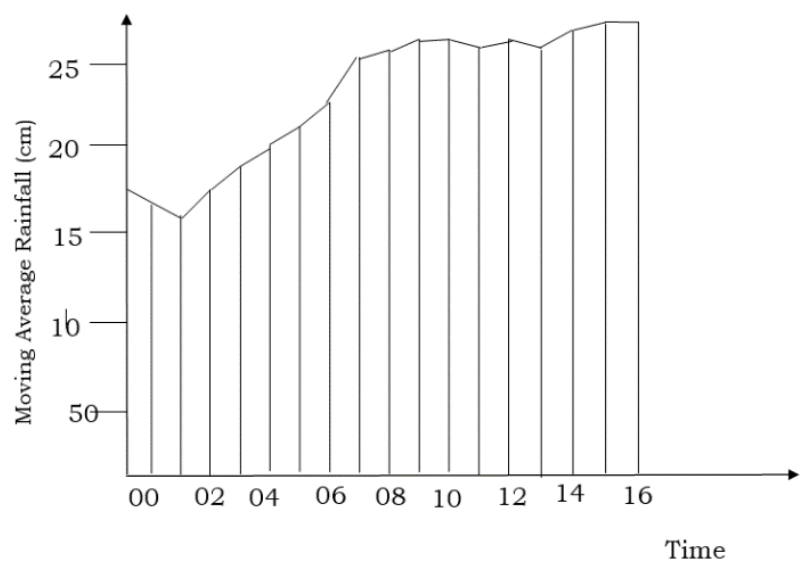

Fig. 3. Moving Average Curve of rainfalls

\section{Hydrological Graphs}

From Table I, it was observed that the greater rains took place in the months of June and July with month of July taking the lead as the heaviest or the rainiest period in the year. The hyetograph can be used to determine the total rain in any period by finding the area closed within the curve. For the monitored storm, the area of the curve was obtained by the help of a planimeter and it is equal to $29.5 \mathrm{~mm}$.

The mass curve in Fig. 2 can be used to determine the rainfall intensity by drawing a tangent at any point on the curve where the rainfall intensity will be determined. At point $\mathrm{A}$, the rainfall intensity in the state was obtained and it is put at $50 \mathrm{~cm} / \mathrm{hr}$. Fig. 3, reveals how the precipitation trend is going within 3 -year pattern. From the figure it was discovered that for the first three years of 2000, 2001 and 2002 , the precipitation fluctuation was much but as the years go by the precipitation stabilized and was on the increase.

Recurrent interval of an event can be obtained either by an empirical or by an analytical method. This research used analytical method in the determination of recurrence interval. From Table IV where the recurrence interval was computed, it was observed that an annual rainfall of magnitude $187.4 \mathrm{~mm}$ has a recurrence interval of 2 years which means it will take 2 years for the $187.4 \mathrm{~mm}$ rainfall to be equalled or exceeded in $17 / 2$ (i.e. 8.5) times for the reviewed period of 17 years with a probability of occurrence 0.50 and $50 \%$ frequency. This prediction is necessary for the design of many engineering systems such as flood control structures, drainage system dams, etc. This analytical method is more useful when many years are considered. This prediction will go a long way to create sustainability in the design of drains with the attendant consequent of designing and constructing drainage systems which can stand the test of time with higher serviceability characteristic of quality and adequate free board.

\section{CONCLUSION AND RECOMMENDATIONS}

\section{A. Conclusion}

Rainfall prediction is very vital in the design of engineering systems and play significant roles in the overall planning and management of water resources. The knowledge of rainfall prediction guides the farmer to all his preparation of activities for any year and helps him to incur less loss that can be caused by drought and over-bearing rains. It guides both government and individuals on the necessary actions to be taken with regards to water on each year. Rainfall prediction has great affinity with weather forecasting and it is a tool employed in transport safety. Hydrological computations require long time data collection which must cover many years. The larger the data used in the hydrological computations the more accurate the predictions arising from them will be. This emphasizes the importance of data collection in hydrological studies and water resources engineering. Hydrological computations have a wide application in water resources development and allocations.

\section{B. Recommendations}

Based on the findings of this research, the following recommendations are made,

(i) This prediction method should be applied when designing flood control systems, drainage systems, dams etc.

(ii) Considerations should be given to rainfall trends in 
all communities in the planning and management of their water systems.

(iii) As a predictive strategy, the government should use this, to study the rainfall characteristics of upcoming years as a proactive approach to save the future.

\section{ACKNOWLEDGMENT}

I want to thank all who contributed in the successful completion of this research work. My foremost appreciation goes to the staff of the Nigerian Institute of Meteorology Sam Mbakwe International Cargo Airport, Owerri for the provision of the rainfall data used in the research. I thank my beloved wife- Mrs Fidelia Nwanneka Law-Obi and all my children for their unquantifiable support extended to me during the period of this work. Finally, I give kudos to my colleagues at the Department of Civil Engineering, Imo State University, Owerri for their understanding and cooperation.

\section{REFERENCES}

[1] K.R. Arora, Irrigation, water power and water resources engineering standard publishers distributors Delhi India, 2007.

[2] Essays, U.K, Analysis of rainfall pattern in Enugu, retrieved from https://www.ukessays.com/essays/ statistics, 2013.

[3] S.K. Garg, Hydrology and water resources khanna publishers New Delhi India, 2010

[4] Meteorological data of the Nigerian institute of meteorology, Sam Mbakwe international cargo airport Owerri, Federal Government of Nigeria, 2017.

[5] L.E. Obi, and Obi-Njoku O. Engineering geology, mezsbedap publishers, Owerri Imo State Nigeria ISBN: 978 - 978 - 54014-7-9, 2016.

[6] L.E. Obi, (2017), Investigation of Hydrometeorological Characteristics of Anambra-Imo River Basin of Nigeria", International Journal of Research in Advanced Engineering and
Technology, ISSN 2455-0876 Impact Factor RSJ 5/44, www.newengineeringjournal.in vol.3 Issue 2, pp. 56-64

[7] H.M. Raghanath, Hydrology, new age international publishers, New Delhi India, 2009

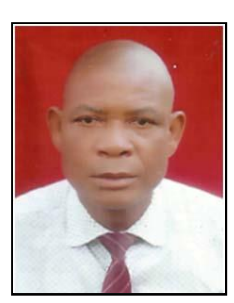

Engr. Dr. Obi Lawrence E.is a native of Ihioma in Orlu, Imo State Nigeria and he is a Senior Lecturer in the Department of Civil Engineering, Imo State University, Owerri. He holds a Ph.D in Civil Engineering from the renowned Federal University of Technology, Owerri, Imo State, Nigeria. He has to his credit Master and Bachelor of Engineering degrees in Civil Engineering obtained in 2006 and 1999 respectively.

$\mathrm{He}$ is an experienced academic who has served as the Head of Civil Engineering Department and through his dint of hardwork and mental prowess facilitated the accreditation of his department by Council for the Regulation of Engineering in Nigeria and the Nigerian Universities Commission. $\mathrm{He}$ is a chartered engineer and belongs to many professional bodies which include Nigerian Society of Engineers, Nigerian Institution of Civil Engineers, Nigerian Institution of Water Resources Engineering, Nigerian Renewable Energy Society, etc. He is a Fellow of the Institute of the Industrial Administration of Nigeria

Engr. Dr .L.E. Obi has published extensively both in local and reputable international journals. He has earned such awards as the best H.O.D. Award for Civil Engineering, Eastern Merit Award for Excellence in Education, Distinguished Leadership Award, Golden General Secretary Award, etc Examples of his publications include-“" Mathematical Application of Simplex Numerical Method in the Allocation of Water in Aboine River Basin of Nigeria", European International Journal of Science and Technology, United Kingdom, Vol. 2 No 5, Pp. 173 - 190", "Development of Model Equations for the Allocation of Water Resources in Anambra Imo River Basin Development Authority of Nigeria, European International Journal of Applied Science and Technology, Kent, United Kingdom". He is currently the Chairman of International Conference in Engineering to be hosted by the Faculty of Engineering Imo State University, Owerri, Nigeria. His areas of interest in research include Optimization of Water Resources Engineering Systems, Modeling of Engineering Systems, Numerical Applications in Water Resources Development and Environmental Engineering. 